\title{
Time and the embodied other in education: A dimension of teachers' everyday judgements of student learning
}

\author{
Silvia Edling ${ }^{1}[$
}

Accepted: 10 August 2021 / Published online: 4 October 2021

(C) The Author(s) 2021, corrected publication 2022

\begin{abstract}
The article explores ethical conceptualisations of time that take the existence of the embodied Other in education into consideration. Kristeva's time/memory paradox is discussed with regard to teachers' everyday judgements in relation to student learning. In conclusion, learning as an unruptured endeavour is impossible when the time of the embodied Other is taken into account. In this sense, teachers need to be aware of: 1) the time gap between people, 2) the time gap between the conscious and subconscious (time/timelessness), 3) the fact that teachers' and students' meaningmaking is always tainted by past memory, 4) the ways in which the timelessness of the subconscious crashes into conscious meaning-making in the present and creates ruptures that affect the content of learning and the life conditions of Others, 5) how frozen time (shadow of time) can be used as a way of learning from ruptures, and 6) that processing time(s) is just as important as 'progressing in it'.
\end{abstract}

Keywords Education - Time · ethics $\cdot$ embodied other

\section{Introduction}

What if - after the Copernican revolution concerning Earth and the Darwinian revolution concerning species - the Freudian revolution were a revolution of the concept of time? (Kristeva 2002, p. 28)

An upper secondary teacher whom we can refer to as Anna approached me after a lecture about equal treatment in education and thanked me for the presentation, while at the same time starting a discussion about the difficulties of engaging in others' well-being when they did not want this engagement. She told me about a student, Sebastian, who had real difficulties in school, both on the social level where he felt an outsider and with schoolwork, where he was way behind his peers in

Silvia Edling

silvia.Edling@hig.se

1 Faculty of Education and Business Studies, University of Gävle, Gävle, Sweden 
progress. Sebastian frequently pointed out that he did not feel well and Anna experienced that she had put her heart and soul into this relationship in order to make him feel included and help him catch up. However, the recurring responses from Sebastian made her sad and distressed, since on several occasions he had returned her gestures with harsh words, calling her stupid, ugly, that she should 'butt off' and pointed fingers at her. The situation has made Anna hateful towards this student whom she feels has betrayed her. She finds these emotions difficult to handle because she does not find them professional and efficient in her daily work. Notwithstanding, the reactions are there, and she is struggling to deal with them. Before leaving she asked me why I did not talk more about these situations in my lectures (cf. Edling 2009).

In this article, a specific ethical conceptualisation of time is highlighted as a means of problematising the inescapable presence of the embodied Other when ideas about teacher judgement and efficient learning are approached in education. Education can be understood as a site for intervention in children's and pupils' lives with a view to hopefully changing them for the better (Biesta 2006). The fact that "[t]here is no education without relations" (Bingham and Sidorkin 2004), and that education fundamentally aims at changing people, brings with it an ethical dimension that pleads for attention. Within the fields of philosophy and education, the instrumental features of learning have recently been questioned and found to be too narrow a conceptual frame to capture the notion of education. Learning is generally described as a phenomenon that successively increases people's amount of knowledge through repetition defined in measurable goals that are already set within a social order, while excluding other forms in which education can be understood and approached (Lewis 2016).

What is of interest here is the way in which learning unavoidably involves an encounter with difference, which problematises the linear and social dimensions on which learning rests. Difference can be understood as difference between groups, often referred to as plurality, and as a radical difference between people (Mouffe 2000). The radical difference between people can also be understood as a distinction between other (autre) in a generic sense, i.e. 'people in general are different', and Other (autrui) stressing a human being who is allotted a unique value and in need of cherishing (Lévinas 1987). Yet, drawing on psychoanalysis, the ethical desire to cherish the Other cannot overlook the Other within us. That is to say, the elusive alterity of the unconscious that constantly keeps disturbing the conscious reasoning of the self in ways that have consequences for the Other (Britzman 1998; Edling 2009; Todd 2003; Uitto and Syrjälä 2008). In the article attention is drawn to the embodied Other, where the Other refers to both the Other before us and the Other within us.

Paying attention to difference, i.e. individual uniqueness or otherness, is central in research on ethics, social justice and education, where it is emphasised that the presence of the Other should be acknowledged if justice is to be taken seriously (cf. Kumashiro 2000; Young 1990). Similarly, a substantial amount of research highlights the Other within us that tends to erupt as disturbing, and often unconscious, bodily reactions in everyday (educational) life, such as speech, body language and actions, in ways that make an impact on someone else's life situation (cf. Britzman 
1998; Todd 2014; Uitto and Syrjälä 2008). However, the article's main interest is not the notion of otherness or embodiment per se, but rather how time can be conceptualised in education as a question of teacher judgement in ways that do not overlook the unavoidable presence of the corporal Other. For Donald Schön (1983), professional judgement is not merely a question of solving problems. Rather, the professional is first expected to interpret (name) and frame the problem in relation to specific conditions embedded in an exclusive present context and only thereafter find one or several ways of dealing with it (p. 42, 315). This is an important focal point, especially in the light of the current tendency towards what in many societies is referred to as a 'cult of efficiency' (Begley and Stefkovich 2004) in which the good management of time is a key point.

The purpose of the article is to elaborate on how Julia Kristeva's notion of a time/ timeless paradox could be fruitful for nuancing teachers' professional judgement with regard to time and the embodied Other in education. The article is divided into three parts. By way of background, the first part considers earlier research on time and the Other and leans on two overlapping theoretical branches of time - the linear and the plural. In relation to Kristeva's writings, the second part gives examples of how the notion of time can contribute to enriching teachers' judgements of the presence of the embodied Other in education. Finally, in the third part a tentative conclusion is presented.

\section{The cult of efficiency}

A vast range of literature addresses the function and role of time in education (cf. Brannen and Nilsen 2002; Duncheon and Tierney 2013; Fitchett and Heafner 2014; Gray 2004; Hunter and Benson 1997; Williams 2011) and educational leadership (Eacotta 2013). What can be noted in the current global educational climate is that words like advancement, testing, input, output, outcome, achievement, measurement and betterment have become more prominent in the aftermath of new worldwide trends in curriculum (cf. Priestley and Biesta 2013), which indirectly risks shaping teachers' conceptualisations of time in relation to their students. As such, time used to structure educational organisations and values at a political level is intimately connected to teachers' day-to-day student relationships and their conceptions of time. Time or theories of temporality are in this way of reasoning not something external to teachers' professional judgements but are unavoidably an integrated part that pleads for attention, since they both help to explain and affect conceptualisations of education and teachers' work (cf. Eacotta and Hodgesb 2014).

It is possible to assert that the interest in time appears to increase in periods when people's desires for order, control and mastery increase (cf. Deleuze 1995; Lingard 2010; Thompson and Cook 2013). These phenomena can be linked to the 'cult of efficiency' coined by Callahan in 1962 when referring to events taking place in America at the turn of the twentieth century, when the progressive era between 1890-1940 was challenged by corporate values drawing on science management and the logic of business. The trend was projected to various social fields in society, not least the field of education where efficiency experts were brought in as 
consultants to increase the outcomes of educational inputs. In his well quoted book from the 1960s, Callahan presents evidence of how the logic of business inevitably collides with the logic of education in ways that raise ethical concerns (Callahan 1962). Although he does not elaborate on how the ethical considerations should be understood and handled, the question of ethics is raised anew by those approaching the wave of efficiency cult flourishing in many contemporary educational societies (Begley and Stefkovich 2004).

It needs to be pointed out that efficiency should not be regarded as the opposite to education and ethics, especially as there are a lot of examples in which an effective organisation facilitates learning and sees to it that people are not harmed (Boyd 2004). Yet, what is pointed out from various directions is that a blind cherishing of efficiency risks increasing inequalities in society and creating situations in which individuals are injured behind a cloak of goodwill (Gándara et al. 2003; Gutierres and Green 2004; Stefkovich and O'Brian 2004).

Indeed, in the efficiency context, time is about effectively taming people's behaviour and organisations in ways that save money and energy, as expressed in Cullingford's (2004) book, The Effective Teacher. The idea that time, in the context of teachers' work, "can be used sensibly" (p. 6), that they should be aware of "wasted time" (p. 17) and that they can learn to organise the "management of time" (16 p), raises several questions, not least whose time is to be protected and managed in an effective way. In one sense, Sebastian mentioned in the introductory quote steals valuable time from Anna, which she can use more efficiently if she ignores him. But is it really ethically defendable to remove subjects that cause inconvenience to teachers in order to save time? If not, perhaps the relationship between time and teachers' judgements should be re-conceptualised?

The objective here is not to provide an absolute overview of how time can be understood, especially as various theories offer different interpretations of time. What is important is that they offer a rough outline of time in relation to the embodied Other in education.

\section{Linear understanding of time and its ways of omitting plural time conceptions}

Linear understandings of time are also known as materialist theories of time (Arthur 2010), substantivalist theories of time (Benovsky 2010), causal theories of time (Smart 1969) or system theories (Nowotny 1992). Linear grids are characterised by seeing time as something concrete, i.e. as a container that is unrelated to what is going on inside it and the plausible changes that might occur. From this standpoint, the container of time is regarded as a singular substantial thing that is shared by everyone and everything and is independent of the people and events taking shape within it (cf. Benovsky 2010). The concreteness of time has also been debated by those who regard the container as a tangible object and claim that the substance of time is an abstract noun, such as a thought or a measure. Nevertheless, what unites linear comprehensions of time is that time existed before humans and that time unites them regardless of place and context (cf. Arthur 2010).

Moreover, knotted within the foundations of linear understandings of time is an assumption of causality, that is to say, a possibility to mechanically measure 
means-ends in everything that is observable, including human action. This way of understanding time is embedded in positivism where, in its most extreme form, it is stressed that all objects and subjects share time in ways that facilitate just comparisons that detect or observe progression over time (cf. Bhaskar 1986). Time in this sense thus becomes disentangled from people's differences, i.e. their specific thoughts, embodiments and deeds.

Education is and has generally been regarded as an arena that enables individuals to progress towards pre-defined goals in ways that presume a shared linear image of time in which they, through educational mastery, slide towards perfection. This ambition, which marks how time is understood and materialised in education, was enhanced by the processes of enlightenment and industrialisation that took shape during the middle of the eighteenth century when Newton's arrow of time was emphasised, stressing a never ending progression towards a better and more fulfilling future (cf. Britzman 1998; Doll 2012; Kristeva 2002; Nowotny 1992; Osberg and Biesta 2010; Slattery 1995; M. Young 1988). However, linear understandings of time have been criticised by advocators of relational understandings of time for their inability to deal with the unavoidable presence of the (embodied) Other in education.

\section{Relational approaches to time}

Although there is a strong tradition within education to cherish linear approaches to time, this has been criticised for being harmful, due to its tendency to de-humanise education. What is pointed out is that a dogmatic focus on time as linearly shared and mechanical overlooks the unique individual's experiences of time and the specific contexts and conditions from which they spring. Consequently, in the conceptualisation of time as 'time as an arrow', ethics tends to be narrowed down to an objective shaping of personalities and behaviour and knowledge about the Other (cf. Fabian 1983; Hunter and Benson 1997) in ways that inconsistently exclude and conceal the very existence of the Other (Fabian 1983; Todd 2003). Moreover, it tends to exclude the political and hence hierarchical dimension of time, where some people have time while others do not (Robson 2015). The inequality that is present in time conceptions is also acknowledged by Alhadeff-Jones (2018), who maintains that an awareness of various time conceptions enables teachers and students to problematise people's experiences of time and how they impact their life conditions. Indeed, by opening up to and stimulating a complex rhythm of being in time, Alhadeff-Jones suggests the possibility for a more emancipatory education.

Consequently, in contrast to the linear view, where time is pictured as something that is independent of human action, the relationalist view emphasises that there would be no time without humans, since time take shape in a system of relations that requires human meaning-making (cf. Benovsky 2010; Edling et. al. 2020a, 2020b). According to Ricoeur (1984), time is unavoidably filtered through people's experiences and can only be rendered meaningful through narratives of reality. Narratives thus bring an awareness that facts about the world are tinted by unique individuals' historical consciousness in the present, which is important to acknowledge for ethical reasons, given that various conceptions (of time) impact people's life conditions. 
In addition, Wehrle (2020) argues that a central human condition of experience involves a double dimension of embodiment (twofold temporality), i.e. being in a body and the experience of having a body experiencing, which she argues is important to pay attention to as it brings with it different ways of existing in time.

In accordance with linear theories, everything that takes shape in life does so simultaneously and can be objectively observed through the senses of individuals. However, this way of reasoning is paradoxical, in that it overlooks the gap between the observer and the observed, which requires interpretation. It also fails to recognise the breach between "actions/events", "before/after"; "tempus/aeternitas", "future/past" and "time measurement/what is being measured" (Nowotny 1992, p. 434). Subsequently, following Nowotny (1989), the belief in the simultaneity of a phenomenon, which de facto is non-simultaneous, creates an "illusion of simultaneity" that begs to be taken seriously when comprehending time in social settings, because the illusion veils the inevitable existence of difference. Moreover, comprehensions of time are important in that they convey messages about how the world is ordered in ways that impact learning and teaching:

Time is not a quality in things, nor invariant across human societies. Nor is it solely the result of a specific human capacity for concept formation in the sense of creating ever more abstract synthetic concepts. It is also a capacity inherent in the social evolutionary process, connected to the ability of learning and the passing on of knowledge to the next generation about how to order events both in sequence and synchrony (Nowotny, 1992, pp. 436-437, the italics are mine).

According to Nowotny (1992), any attempt to find a theory of time that encompasses the Other needs to distance itself from time as an essence within humans and humanity at large, because it then automatically excludes or eliminates otherness. Thus, every attempt to fix and order time in linear ways boils down to the question of whose time should embrace people's life experiences. Or, as Frankenberg (1988) asks in the title of his chapter, "[y]our time or mine?".

Contrary to the similarity embedded in linear images of time, relationalist theories attempt to open up for a plurality of time conceptions (Fabian 1983; Frankenberg 1988; Nowotny 1992; M. Young 1988). Plurality can be understood in terms of various groups in society or radical difference between people (Mouffe 2000). Whereas Young (1988) explores how various time rhythms develop amongst different groups in society depending on the context, Fabian (1983) takes the notion of time-plurality a step further by referring to Lévinas' notion of the radical Other. Following Fabian, time is not only a plural creation that divides various cultural groups depending on their current purposes and conditions but can also be understood in relation to otherness, where the lapse between the Other implies being separated in time in ways that rupture every attempt to treat time as unified.

Notwithstanding, it is important to underline that the distinction between linear perspectives of time and relationalist standpoints should not be seen as absolute opposites in a dualistic sense. On the contrary, different perceptions of time supplement each other: "[t]his means that the predominantly linear time is complemented by greater awareness of cyclical times and temporal routines which are overlapping 
each other" (Nowotny, 1992, p. 445). Subsequently, every attempt to fix time to an -ism risks being counter-productive, in that no -ism can capture the totality of human complexity and function in an inclusive/exclusive way (cf. Hunter \& Benson 1997).

What relationalist theories of time provide are arguments for why time in relation to the embodied Other is important to highlight and include in education. Comprehensions of time are important, in that they convey messages about how the world is ordered in ways that impact learning and teaching (Nowotny 1992, pp. 436-437). The relational conceptions of time can be said to present a framework that problematises the sole focus of trying to know others in education and instead opens up for notions of sensitivity in teacher judgement, which tentatively suggests that another way of grasping time is at play, instead of the linear (Edling \& Frelin, 2016; Frelin 2014).

A central issue in this article is to explore how time can be ethically conceptualised in education without overlooking the corporal Other. Over the years, substantial research has been conducted on the embodied dimension of time. For example, Sengupta's (2018) article 'How embodied is time?' aims to map how embodied minds arrange temporal events. The intention is to overcome the 'violation' of linear and causal time. In a review of a broad spectrum of research about how embodied emotions impact time judgement, Droit-Volet et. al. (2013) show that embodied emotions of time mainly seem to have been explored in the field of brain and behavioural research striving to depict the mechanisms between emotions and time judgements. They also stress that more research needs to be conducted in the field, especially in relation to how emotions are shaped by dynamic environments and their influence on time judgement.

In order to deepen the embodied dimension of time in education, Kristeva's time/ memory paradox has been explored as an example of plural timeframes that have been presented and developed in relation to addressing and problematising the presence of the embodied Other from an ethical perspective.

\section{The time/memory paradox in education}

Kristeva (Kristeva 2000) looks at time as an embodied experience that takes shape in the clash between the inner/outer or the unconscious/conscious. The Other is thus comprehended in a dual sense as a radical difference between people and within people (Todd 2003), which implies that:

- there is a time gap between the inner/outer, i.e. unconscious/conscious

- the present cannot be captured outside memory

- the unconscious nestles into the conscious timeline, creating ruptures that affect meaning-making and people's life conditions in unforeseen ways

- the possibility for process requires a shadow of time

- process becomes significant to attend to and is not just progression.

Kristeva approaches ethics, time and the Other by turning to phenomenology and psychoanalysis. Her exploration of time is primarily directed towards making meaning out of a unique subject's outer/inner interpretations and the consequences this 
has for Others. Interpreting Kristeva (2002), there is an unbridgeable gap between myself and the object; that is between me and the way I make meaning of the world, including myself. It is in this gap, which she refers to as a metaphor stationed between the outer/inner or conscious/subconscious, that the notion of time/ timeless takes shape. Her image of time can be useful in that it opens up a space in which conditions for existing as bodies in present educational settings are able to be explored.

The situation with Anna and Sebastian outlined in the introduction indicates that something is taking place between them that the linear timeline cannot properly capture or interpret. Anna wants to help Sebastian to develop his learning, whereas Sebastian demonstrates resistance. It is obvious that they see and experience the world differently and struggle with strong emotions that colour their reactions to one and others.

The gap between the outer/inner implies that in order to make sense of the world the subject first needs to interpret it. It is through this process of interpretation that past experiences tend to unconsciously nestle into the practice of meaning-making. In other words, according to Kristeva (2002) the subject is always balancing on the verge of time/memory (p. 33). Understanding the time/memory paradox means that the conscious/unconscious cannot be grasped as though we are anchored in the present and acknowledging or opening up for the forces of the unconscious. The emphasis on the present not only overlooks the fact that the individual has past experiences but also that, and perhaps even more importantly, the present cannot be captured at all outside of memory. Hence, as soon as we have managed to make meaning out of an event, the 'present' time has passed. For this reason, she argues, another logic is required than that which can be found in conscious time. In order to find this logic she turns to Heidegger and Freud.

Contrary to theories that intermingle time with the social, Heidegger's thoughts stand out with regard to relational theorists in the way he maintains that time exists before the social influence of subjects, thus implying that time is an ontological entity. The present, what takes place now and that we consciously recognise as present, is nothing other than a past, in the sense that our conscious reflections always come when the deed is done. The subject does and reflects, but doing precedes the reflection, which implies that the subject is always ahead-of-itself. So, although we categorise the world in terms of past, present and future, reducing the human subject

to these categories becomes problematic, because it cannot capture the past $/ \mathrm{mem}$ ory paradox (p. 29). If this is the case, time itself must come before consciousness. So, even if we categorise the world in terms of past, present and future, reducing the human subject to these categories becomes problematic. Heidegger, together with Freud, underlines that the world does not begin with a word - because that would mean that the world began with humans' meaning-making - but rather proclaims that it begins with an "extrasubjective and extraexistential temporality" (p. 29).

In this sense, Sebastian's and Anna's responses are filtered through their previous unique experiences that erupt from their embodied memory. Anna does not know why Sebastian treats her the way he does, even though she tries to promote his learning, which implies that there is a gap between the two. Although she feels that it is not professional to let her emotions gain the upper hand, she cannot help hating 
Sebastian for his reactions, which in turn makes her feel ashamed, thus indicating a gap inside her conscious and subconscious self as well.

The flow of action in the unique present is always in a sense manoeuvred from a past position (see also Britzman 1998, 2014) and divided from the present by an unbridgeable gap (metaphor). As such, there is no clear distinction between knowledge and values and the conscious and unconscious. Instead, there is an endless intermix, where ambitions to teach in various ways are tainted by teachers' past experiences: " "the other half' of education that works through the teacher's personality indirectly affect[s] the student's development of personality" (Shiho 2012, p. 82). Similarly, the time/memory paradox in education also directs attention to students' learning, which can never simply be narrowed down to a smooth accumulation of knowledge, but also needs to acknowledge transference, i.e. fresh interpretations of past struggles, which in turn require a processing of teachers' and students' verbal and non-verbal expressions in retrospect (Britzman and Pitt 1996, Todd 2003).

If there is a split between a person's inner/outer life, time cannot solely operate on a conscious and shared time scale. Turning to Freud, Kristeva highlights the relationship between timelessness, Zietlos and time. The linear timescale of past, present and future represents a conscious image of time. With the aid of the conscious timeline, it becomes possible to detect moments when the logic of the conscious is ruptured through the disturbance of the unconscious embedded in past experiences. The ruptures are not inscriptions on a solid timeline, but events that cause change in one way or another, e.g. rupturing marks of time that alter its meaning. This suggests that although we cling to the past, present and future tenses, their meaning and our way of being 'in' them takes a different turn through ruptures. Although the attention in Kristeva's (2002) reasoning is directed to the past, it does not mean that the future is forgotten. Questionings of the past carry the potential to lead to transgression and, subsequently, renewal, and it is in this renewal that the revolt of time takes place. Or to put it differently, it is by constantly paying attention to and processing the ruptures of time caused by the timeless that possibilities to reshape the future can take form (Kristeva 2002, p. 25). Accordingly, it is only when Anna and Sebastian return to their reactions and thoughts that they are able to process them and hopefully approach them and the Other differently.

Timeless is described as scandalous temporality, which means a temporality that is detained, functions as an impediment and works through the conscious. Here, time is understood as an autonomous variable, where the purpose is not to reach beyond a certain time, for example as soon as we become mature we become responsible, but to introduce the labour and process of death and rebirth to the conscious model of time. This suggests that (Anna's) teacher judgement is not merely a trait that can be polished to perfection but something that involves a constant and sometimes difficult processing of difference, both when encountering others and when encountering her past memories buried in the subconscious. Similarly, student learning is not always a smooth operation but often involves struggles, resistance and strong emotions of irritation and at times even hatred. Interpreting Kristeva, Sebastian's reactions are just like Anna's and erupt from his time/memory. They cannot merely be judged from an exterior point of view but plead for a time/space of their own. This does not mean that they should necessarily be accepted, rather that they cannot be objectively 
judged from a social point of view without taking his time/memory paradox into account.

In order to gain access to the timeless, we have to become emancipated from the "symptom of being conscious" (p. 27). For instance, it is not enough to focus on how a professional or a student should be. We also need to take the reactions that erupt independently of the 'shoulds' into account. Likewise, in order to approach timeless time as we know it it needs to die - become unbound - in order to be sensitive to drives (pp. 32-33, 36). From Anna's point of view, it becomes important to acknowledge that she actually hates Sebastian, i.e. that he triggers strong emotions in her. Kristeva (2002) distinguishes between thought and imaginary in relation to time. In the conscious present (time and space) there is a tension and an unbridgeable break between what is real (the experience before the image) and what is unreal (that which is absent or unthought-of). The relation between times of reality and unreality is paradoxical, in that the tension can never be erased and the reason for this tension is the existence of the split subject that is only capable of perceiving a mirror reflection of "I" and, consequently, a mirror reflection of the world and the objects in it. Between the times of the real and unreal a third time emerges, which Kristeva refers to as the shadow of time that does not flow. This shadow of time is the time of the imaginary (p. 175). The fruits of the imaginary, or images, become momentarily frozen and cease to flow and hence become possible to interpret. Hence, the story that Anna told can be understood as a frozen image in which the shadow of time becomes possible to approach, interpret and process. In this story, Sebastian's frozen image is lacking. In this sense, students and "teachers are being asked to cast the time of their learning forward and backward. The casting is interminable as the working through of one's own unresolved conflict" (Britzman and Pitt 1996, p. 118).

Finally, simply viewing time in education through the grid of linear theories and the efficiency cult can lead to the assumption that people share the same timeline in ways that implicitly suggest that they are the same and progress in the same way. Moreover, there is no time and place for ruptures, strong emotions and resistance in the efficiency cult, which risks turning Sebastian's and Anna's emotions into obstacles that need to be overcome in one way or another. What Kristeva reminds us about is that the time/memory paradox does not disperse simply by naming/framing time as being shared and efficient (see also Edling and Frelin, 2013), but rather that the time/memory paradox continues to exist in the shadows and influences the present.

\section{Final considerations}

Drawing on Donald Schön's (1983) research, teachers' day-to-day judgements are an intermixture of seeing-as and doing-as. This requires teachers to broaden and problematise their seeing in order to facilitate more elaborate judgements (doing) in the present. According to Schön, the possibility of developing teachers' seeing requires the ability to name what takes place in practice and ponder on the consequences. 
Ethical conceptualisations of naming and framing time are at the centre of this article, with a particular focus on the presence of the embodied Other.

Currently, the field of education seems to be influenced by a cult of efficiency (Begley and Stefkovich 2004) and characterised by terms like input, output, advancement and betterment. The term cult of efficiency, coined in the 1960s, places a particular way of understanding time at the focal point of attention, i.e. time as a commodity that can be managed so that it is not wasted and where it is rationalised and used in a cost-effective way (Cullingford 2004). From this perspective, the image of time is universal and linear, where students and teachers in education are regarded as being governed by similar laws, standing on the arrow of time and progressing towards the same ideal destination (cf. Britzman 1998; Doll, 2012; Kristeva 2002; Nowotny 1992; Osberg and Biesta 2010; Slattery 1995).

Numerous articles have been published over the years problematising the linear/ universal image of time from an ethical point of view within the field of education. It is stressed by some that this is based on an illusion, because it overlooks the human condition of meaning-making that is embedded in teaching and learning (Nowotny 1989) and the existential dimension of time as being impossible to approach outside human experiences filtered through narratives (Ricoeur 1984). As such, the linear/ universal timeframe is incapable of taking the unique Other (Fabian 1983), plural ways of grasping time (Young 1988), the political (Robson 2015) and the emancipatory dimension (Alhadeff-Jones 2018) into account - to mention a few examples. At the same time, there is ample evidence to suggest that a systematic exclusion of human difference risks harming people (see for example Lévinas 1981; Bauman 1995, 2000; Young 1990).

Although time and the Other have been touched on in previous research, hardly any literature draws attention to how time can be understood in relation to the presence of the embodied Other outside the field of brain and behavioural science, which tends to regard linear time conceptions as the norm. Subsequently, from an ethical perspective, this article contributes to the relational and plural approaches to time by exploring how Julia Kristeva's concept of the time/timeless paradox could be fruitful for nuancing teachers' professional judgement further with regard to time and the embodied Other in education.

In conclusion, an ethical responsibility for the embodied Other requires teachers who are aware of: 1) the time gap between people, 2) the time gap between the conscious and subconscious (time/timelessness), 3) the fact that teachers' and students' meaning-making is always tainted by past memory, 4) the ways in which the timelessness of the subconscious crashes into conscious meaning-making in the present and creates ruptures that affect the content of learning and Others' life conditions, 5) how frozen time (shadow of time) can be used to learn from ruptures and 6) that processing time(s) is just as important as 'progressing in it'. Indeed, what the case example at the beginning of the article illustrates is a phenomenon in which teachers and students not only progress, but at times experience seemingly irrational bodily reactions that impact on the outcome of education and thus demands attention. The awareness of a gap between reality and meaning-making (experiencing) has already been stressed in previous research (see for example Nowotny 1989; Ricoeur 1984). However, Kristeva enhances the ethical dimension of embodily existing in time by 
reminding the reader to be attentive to how ruptures continuously impact the life condition of the Other and the importance of paying attention to frozen time as a means of processing and learning from the past ruptures for the sake of the present Other.

Finally, the intention with this article has not been to demonise universal images of time in favour of the plural, or to argue for the need to exchange the latter with the former. On the contrary, the complex features of education call for various explanation models that can deal with different purposes and desires. However, it is argued that the enhancement of the cult of efficiency in the current educational landscape risks reducing time to a universal commodity that needs to be managed in ways that save money and (teachers') energy in ways that overlook the presence of the embodied Other. Here, time is solely treated as linear, conscious and shared, and in this cult of (time) efficiency there is no place for the Other, who is regarded as a disturbing entity that needs to learn to behave according to certain principles and a set schedule. To quote the teacher Anna: "Why don't you talk more about these situations in your lectures".

Funding Open access funding provided by University of Gävle.

Open Access This article is licensed under a Creative Commons Attribution 4.0 International License, which permits use, sharing, adaptation, distribution and reproduction in any medium or format, as long as you give appropriate credit to the original author(s) and the source, provide a link to the Creative Commons licence, and indicate if changes were made. The images or other third party material in this article are included in the article's Creative Commons licence, unless indicated otherwise in a credit line to the material. If material is not included in the article's Creative Commons licence and your intended use is not permitted by statutory regulation or exceeds the permitted use, you will need to obtain permission directly from the copyright holder. To view a copy of this licence, visit http://creativecommons.org/licen ses/by/4.0/.

\section{References}

Alhadeff-Jones, Michel. 2018. Time and the rhythms of emancipatory education. Rethinking the temporal complexity of self and society. London: Routledge.

Arthur, Richard. 2010. Materialist theories of time. Amsterdam: Rodopi.

Bauman, Zygmunt. 1995. Dream of purity. Theoria: A Journal of Social and Political Theory 86 (1995): 49-60.

Bauman, Zygmunt. 2000. Modernity and the Holocaust. Ithaca: Cornell University Press.

Begley, Paul, and Jaqueline Stefkovich. 2004. Education, ethics and the "cult of effeciency": Implications for values and leadership. Journal of Educational Administration 42 (2): 1-286.

Benovsky, Jiri. 2010. The relationist and substantivalist theories of time: Foes or friends? European Journal of Philosophy 19 (4): 491-506.

Bhaskar, R. 1986. Scientific realism and human emancipation. London: Verso.

Biesta, Gert. 2006. Beyond learning: Democratic education for a human future. Boulder: Paradigm Publisher.

Bingham, Charles W., and Alexander M. Sidorkin. 2004. No education without relation. New York: P. Lang.

Boyd, Lowe, William. 2004. Are education and efficiency "antitethical"? Education for democracy vs the "cult of efficiency". Journal of Educational Administration 42 (2): 160-173. 
Brannen, J., and A. Nilsen. 2002. Young people's time perspectives: From youth to adulthood. Sociology 36 (3): 513-537.

Britzman, Deborah. 1998. Lost subjects, contested objects: Toward a psychoanalytic inquiry of learning. Albany: State University of New York Press.

Britzman, Deborah. 2014. That other scene of pedagogy: A psychoanalytic narrative. Changing English 21 (2): 122-130.

Britzman, Deborah, and Alice Pitt. 1996. Pedagogy and transference: Casting the past of learning into the presence of teaching. Theory into Practice 35 (2): 116-123.

Callahan, E Reymond. 1962. Education and the cult of efficiency. Chicago: The University of Chicago Press.

Cullingford, Cedric. 2004. The effective teacher. London: Cassell Education.

Deleuze, G. 1995. Control and becoming. New York: Columbia University Press.

Droit-Volet, S., S. Fayolle, M. Lamotte, and S. Gil. 2013. Time, emotion and the embodiment of timing. Timing \& Time Perception 1 (1): 99-126. https://doi.org/10.1163/22134468-00002004.

Doll, William, Jr. 2012. Pragmatism, post-modernism, and complexity theory. The "Fascinating imaginative realm" of William E. Doll, Jr. New York: Routledge, Taylor and Francis Group.

Duncheon, J.C., and W.G. Tierney. 2013. Changing conceptions of time: Implications for educational research and practice. Review of Educational Research 83 (2): 236-272.

Eacotta, Scott. 2013. Leadership' and the social: Time, space and the epistemic. International Journal of Educational Management 27 (1): 91-101.

Eacotta, Scott, and Kimbalee Hodgesb. 2014. The generative temporality of teaching under revision. Critical Studies in Education 55 (3): 289-302.

Edling, Silvia. 2009. Ruptured narratives: An analysis of the contradictions within young people's responses to issues of personal responsibility and social violence within an educational context. Diss. Uppsala: Acta Universitatis Upsaliensis (AUU).

Edling, S. and Frelin, A. 2013. Doing good?: Interpreting teachers' given and felt responsibilities for pupils' well-being in an age of measurement. Teachers and Teaching: Theory and Practice 19 (4): 419-432.

Edling, Silvia och and Frelin, Anneli. 2016. Sensing as an ethical dimension in teacher professionality. Jornal of Moral Education 45: 46-58.

Edling, Silvia, Sharp, Heather, Ammert, Niklas and Löfström, Jan. 2020b. Why is ethics important in history education? A dialogue between the various ways of understanding the relationship between ethics and historical consciousness. Ethics and Education 15 (3): 336-354.

Edling, Silvia, Sharp, Heather, Löfström, Jan and Ammert, Niklas. 2020a. The good citizen: Revisiting moral motivations for introducing historical consciousness in history education drawing on the writings of Gadamer. Citizenship, Social and Economics Education 19 (2): 133-150.

Fabian, J. 1983. Time and the other: How anthropology makes its objects. New York: Columbia University Press.

Fitchett, Paul, and Tina Heafner. 2014. An analysis of time prioritization for social studies in elementary school classrooms. Journal of Curriculum and Instruction 8 (2): 7-35.

Frankenberg, R. 1988. Your time or mine? An anthropological view of the tragic temporal contradictions of biomedical practice. London: Routledge.

Frelin, Anneli. (2014). Professionally present - Highlighting the temporal aspects of teachers' professional judgements. Teacher Development: An International Journal of Teachers' Professional Development 18 (2): 264-273.

Gándara, P., Rumberger, R., Maxwell-Jolly, J., and Callahan, R. 2003. English learners in California schools. Unequal recources, unequal outcomes. Education Policy Analysis Archives 11 (36): 1-54.

Gray, Sandra Leaton. 2004. Defining the future: An interrogation of education and time. British Journal of Sociology of Education 25 (3): 323-340.

Gutierres, Kathrine, and Green, Preston. 2004. Re-examining race-based admissions processes of American institutions of higher education using multi-dimensional ethical perspectives. Journal of Educational Administration 42 (2): 236-248.

Hunter, William, and Gart Benson. 1997. Arrows in time: The misapplication of chaos theory education. Journal of Curriculum Studies 29 (1): 87-100.

Kristeva, Julia. 2000. The sense and non-sense of revolt. New York: Columbia University Press.

Kristeva, Julia. 2002. Intimate revolt: And the future of revolt. New York: Columbia University Press.

Kumashiro, Kevin. 2000. Towards a theory of anti-oppressive education. Review of Educational Research 70 (1): $25-53$. 
Lévinas, Emmanuel. 1987. Time and the other and additional essays. Pittsburgh: Duquesne University Press.

Lévinas, Emmanuel. 1981. Otherwise than being: Or, beyond essence. Dordrecht: Kluwer Academic.

Lewis, Tyson. 2016. Study time: Heidegger and the temporality of education. Journal of Philosophy of Education 51 (1): 230-247.

Lingard, Bob. 2010. Policy borrowing, policy learning: Testing times in Australian schooling. Critical Studies in Education 51 (2): 129-145.

Mouffe, Chantal. 2000. The democratic paradox. London: Verso.

Nowotny, Helga. 1989. Mind, technologies, and collective time consciousness. Madison: International University Press.

Nowotny, Helga. 1992. Time and social theory: Towards a social theory of time. Time and Society 1 (3): 421-454.

Osberg, Deborah, and Gert Biesta. 2010. Complexity theory and the politics of education. Rotterdam: Sense Publishers.

Priestley, Mark, and Gert Biesta, eds. 2013. Reinventing the curriculum. New trends in curriculum policy and practice. London: Bloomsbury Academic.

Ricoeur, Paul. 1984. Time and narrative (Vol. 1). Chicago: University of Chicago Press.

Robson, Mark (2015). Jacques Rancière and time: 'Le temps d'après.' Paragraph, 38(3), pp. 297311. www.jstor.org/stable/44016385. Accessed 30 July 2021.

Sengupta, Rangesh. 2018. How embodied is time? Journal of Indian Council of Philosophical Research 35: 431-445.

Schön, Donald A. 1983. The reflective practitioner : How professionals think in action. New York: Basic Books.

Shiho, Main. 2012. 'The other half' of education: Unconscious education of children. Educational Philosophy and Theory 44 (1): 82-95.

Slattery, Patrick. 1995. A postmodern vision of time and learning: A response to the National Education Commission Report Prisoners of Time. Harvard Educational Review 65 (4): 612-633.

Smart, J. 1969. Casual theories of time. The Monist 53 (3): 385-395.

Stefkovich, Jacqueline, Anna, and O'Brian, G. Michaele. 2004. Best interest of student: An ethical model. Journal of Educational Administration 42 (2): 197-214.

Thompson, Greg, and Ian Cook. 2013. Education policy-making and time. Journal of Education Policy 29 (5): 700-715.

Todd, Sharon. 2003. Learning from the other Levinas. Psychoanalysis, and ethical possibilities in education. Albany: State University of New York Press.

Todd, Sharon. 2014. Between Body and Spirit: The liminality of pedagogical relationships. Journal of Philosophy of Education 48 (2): 232-245.

Uitto, Minna, and Leena Syrjälä. 2008. Body, caring and power in teacher-pupil relationships: Encounters in former pupils' memories. Scandinavian Journal of Educational Research 52 (4): 355-371.

Wehrle, Maren. 2020. Being a body and having a body. The twofold temporality of embodied intentionality. Phenomenology and the Cognitive Science 19: 499-521. https://doi.org/10.1007/ s11097-019-09610-z.

Williams, J. 2011. Gilles Deleuze's philosophy of time: A critical introduction and guide. Edinburgh: Edinburgh University Press.

Young, Iris Marion. 1990. Justice and the politics of difference. Princeton: Princeton Univ. Press.

Young, Michael. 1988. The metronomic society. Natural rhythms and human time tables. London: Thames and Hudson.

Publisher's note Springer Nature remains neutral with regard to jurisdictional claims in published maps and institutional affiliations. 